\title{
Effective Factors on Behavior Tendency in the Acceptance of Electronic Banking Based on Planned Behavior Model (TPB)
}

\author{
Shahram Gilaninia (Corresponding author) \\ Department of Industrial Management, Rasht Branch \\ Islamic Azad University, Rasht, Iran \\ Tel: +98-911-335-6977_E-mail: gilani_sh45@yahoo.com \\ Hamidreaza Alipour \\ Islamic Azad University, Rasht Branch \\ Rasht, Iran \\ Peyman Rahpeyma \\ Department of Business management, Rasht Branch \\ Islamic Azad University, Rasht, Iran \\ Seyyed Javad Mousavian \\ Department of Management, Astara Branch \\ Islamic Azad University, Astara, Iran \\ Tel: +98-911-335-4617_E-mail:saba_moosaviyan@yahoo.com
}

$\begin{array}{lr}\text { Received: August 8, } 2011 & \text { Accepted: August 24, } 2011 \quad \text { Published: November 21, } 2011 \\ \text { doi:10.5430/ijba.v2n4p54 } & \text { URL: http://dx.doi.org/10.5430/ ijba.v2n4p54 }\end{array}$

\begin{abstract}
Now part in growing of the customers is emerging who are interested their banking systems by using the internet and without going to court to do. In this study, research is intended to understand what factors are influencing on the behavioral tendency to accept electronic banking. So three hypothesis was adjusted there is a relation between (1-Attitude to behavior, 2-subjective norm 3- Perceived behavioral control and behavioral tendency in the electronic banking). Statistical research community is all users of Internet banking services bank in Iran (Rasht). The sampling method is availability Non-probable. Data collected from questionnaires and as field. Hypothesis test measure by the correlation coefficient that all hypotheses were confirmed.
\end{abstract}

Keywords: Attitude Behavior, Subjective Norm, Perceived Behavioral Control, Electronic Banking

\section{Introduction}

Looking deeper into the business and service enterprises certainly can be said the customer was and is the capital and philosophy of this institution. Banks are one of the most obvious of these services, all customers want is a service provided by banks in accordance with their expectations. IN fact, what is the quality of banks certainly their succeeded is in discovering the needs and expectations of clients and service delivery based on the demands. According to the importance of the customer service organizations, especially banks, the competition for most customers, gradually they have become one of the main pillars of bank management. Nowadays, Information Technologies have been regarded as the most useful part of industry, economics as well as culture, so that they have partaken in $60 \%$ of the industries all over the world. While the power of information technology is increasing in an outstanding way, its users and the mangers in organizations face some problems like the reluctant end- users of information systems. It is worthwhile to mention that the use of these systems will bring about some important functional advantages if they being used correctly (Amirkhani et al., 2011) 
Electronic banking includes all the electronic channels that customers use to access their accounts and transfer funds between accounts or pay their bills. These channels include the internet, mobile, phones and devices to ATMs (Leo,et al,2003). Many studies published on Internet banking are mostly related with internet banking adoption and acceptance, security and risks of online banking system and interface designs (Bauer \& Hein, 2006; Cheng et al., 2006; Claessens et al., 2002; Lai \& Li, 2004;Luarn \& Lin, 2005; Suh \& Han, 2002; Weir et al., 2006). However,to our knowledge, there are only a limited number of studies that examines the differences and similarities between other banking channels and Internet banking. Mols (1998) compared users of PCbased banking systems with non-users. Wisner and Corney (2001) identified Internet bank sites, evaluated them with respect to the customer feedback capabilities, and made comparisons between the brick and mortar and Internet banking. Yakhlef (2001) explored the changes in implementing Internet and determined how these changes affected the brick and mortar distribution channels of banks. Akinci, Aksoy, and Atilgan (2004) conducted a survey to develop an understanding of consumer's attitudes and identified whether a significant difference existed among demographic profiles and attitudes of Internet banking users and nonusers. The results reveal that there are significant differences between users and non-users, and that the most important three attributes in customers' bank selection processes were related to security, reliability, and privacy issues. On the basis of the similarities between web-based bank services, four categories of services were defined. These categories include information services, money transfers (EFT and payments), investment services (stock, bond, and mutual funds), and repo and currency exchange services. One relevant study to the current work was conducted by Thornton and White (2001) to investigate whether particular attitudinal variables affect the usage level of ATMs, electronic fund transfer at point of sale (EFTPOS), credit cards, cheques, human tellers, Internet banking, and telephone banking. They found that customer orientations such as convenience, service, technology, change, knowledge, computer, and Internet influenced the usage of different channels. The usage of ATM, EFTPOS, and telephone increased, as customers were more oriented toward change, knowledge, computer, and confidence. Fethi Calisir and Cigdem Altin Gumussoy (2008) Examines how young consumers perceive Internet banking in relation to other six banking channels (brick and mortar, automated teller machine (ATM), phone banking, wireless application protocol (WAP), electronic fund transfer at point of sale (EFTPOS), and bank branches in stores). Correspondence analysis and cluster analysis revealed the banking channels that are close with Internet banking. The results indicate that Internet banking, ATM, and phone banking substitute each other. The results also show that Internet banking is considered to be efficient for ease of use and access, and that the users of Internet banking lack confidence in the security of the web sites of Internet banking.

In this study is focusing on internet banking. Given the increasingly large banks in developed countries and developing countries to provide banking services through electronic channels and development banks and financial institutions of virtual has increased competition in the banking industry. So that other banks are also trying to develop different approaches to electronic banking. Information technology improvements are meant to replace traditional face to face services to modern technology service. In the industry of financial services, due broken rules and systems and develop information and communications technology. Most financial institutions have turned to transform the traditional approach to new approaches. This deformation resulted in savings of 25 to 30 percent of financial costs of banks in particular are using internet banking. (Shao, Hosan, \& Ying, 2008, p274). According to the above topics, researcher seeks to answer the following question:

What is factors influencing on behavioral tend to accept electronic banking?

\section{Theoretical Framework}

Over the last few decades, more research attention to the usefulness and ease of use as determinants acceptance of information systems and information and communication technology by customers. These structures are the basis and foundation of the technology acceptance model (TAM).Technology acceptance models one of the models that extensively and widespread for describe the factors influencing the acceptance of information systems and information and communication technology is used by users and customers. Technology acceptance model to determine factors affecting IT adoption by users of information systems in 1989 is presented by Davis. Technology acceptance model based on Fishbein and Ajzen is as the theory of rational action (TRA). Logical action theory is a general model that is expressed: Attitude of individual is determines their social behavior. Attitude will be function of the beliefs of people about the results behavior and the evaluation this results. In the model of Technology acceptance implementation of a theory of rational action for modeling acceptance of information systems done by users.Two perception based on previous studies, make the basic technology .The two perceived order of perceived usefulness and perceived ease of use. (Taylor\&Todd, 1995, p.144 )The theory of planned behavior(TPB) underlying the effort of TRA has been proven successful in predicting and explaining human behavior across various information technologies (Ajzen, 2002, 1991). According to TPB, a person's actual behavior in performing certain actions is directly influenced by his or her behavioral intention and, in turn, is jointly determined by his or her attitude, subjective norms and perceived behavioral controls toward performing the behavior. 
Behavioral intention is a measure of the strength of one's willingness to exert effort while performing certain behaviors. In essence, TPB differs from TRA in that it has the additional component of perceived behavior control. (Ming-Chi Lee, 2009) .TPB, In fact developed model is reasonable action theory. Both theory states that behavior is a direct result of behavioral tendencies. The theory of rational action, intention and desire is modeled of attitude and subjective norm.

As a general rule, in this model a positive attitude towards work, optimal subjective norms, and high perceived behavioral control, causes that person going to be doing the behavior.

\section{$<$ Figure 1 about here $>$}

According to the theory of planned behavior, causes behavioral beliefs and evaluation of results, good or bad attitude towards performing behavior in person. Result of normative beliefs and motivation to fulfill the normative expectations of others will be in subjective norm and control beliefs determine perceived behavioral control. Overall attitudes about the behavior, subjective norm, and perceived behavioral control lead to the formation of behavior are going to performing. In Several studies theory of planned behavior was used as the basis of theoretical research.

\subsection{Perceived Behavioral Control}

In theory of planned behavior reflect perceptions of internal and external constraints of performing behavior. (Taylor, \& Tod, 1995, p 149). Understanding of the factors is known for facilitate or prevent performing behavior as control beliefs that these factors include the internal control factors (Information, skills and abilities of individual) and outside control factors (Opportunities, resources and facilities) (Kener, Armitaj, 1998, p430-432). But generally for use of any technology, there are important factors in control. In theory of planned behavior are examined to determine according to the study of technology, factors that control the use of certain terms. (Mathieson, 1991, p179)

\subsection{Attitude Behavior}

That person has a positive vision towards performing of behavior .It is a psychological tendency that by evaluating a particular behavior is determined by the degree of favor or not favor.

\subsection{Subjective Norm}

Person feels social pressure to do is behave. Perceived social pressure to do or not is a specific behavior. Looks at the influence of people in one's social environment on his/her behavioral intentions; the beliefs of people, weighted by the importance one attributes to each of their opinions, will influence one's behavioral intention.

\subsection{Electronic Banking}

Simple definition: Electronic money + Electronic transfer of resources= Electronic banking

The potential of on-line or Internet Banking was well recognized a decade ago (Booz \& Allen Hamilton, 1997; Deloitte Consulting, 1998) when key institutions began to align the product delivery mix with new technology and explore and exploit new approaches to their business. Internet Banking is multifaceted and impacted by changes in such technology, deregulation of many parts of finance, the emergence of new banking institutions and economic restructuring. Such environmental changes are forcing banks to reassess their costs and profit structures, in attempts to remain profitable, reduce operating expenses and maintain strict control of costs. As such, many banking executives perceived technology as the key solution for controlling costs (Dannenberg \& Kellner, 1998; Giannakoudi, 1999; Kalakota \& Whinston, 1997). Traditionally this has been through "Extranet banking', i.e. access through a private network between the bank and customers and "Dial-up banking'” where access to the bank's server is by dial-up modem (Aladwani, 2001). However, these services require the installation of specific telecommunication networks or application software, e.g. Electronic banking can be introduced ,the use of technology networks development and telecommunications for transferring resources (money) in the banking system.Development of electronic banking began in the second half of the twentieth century .Technology development and the development of electronic infrastructure, telecommunications and computer and telecommunications networks, The main driving force behind the transformation of traditional banking systems (paper) to be considered electronic banking. In electronic banking through the communication line has been and effect of transactions is on the instantaneous accounts. No need for paper records. Many activities are performed in the common banking system. In electronic banking performed by the computer and its peripherals and therefore operational structure of the banks has experienced major changes. (Boniadi, 2007, p 6). However, Internet Banking, defined as "the delivery of banking services through the open-access computer network (the Internet ) directly to customers' home or private address' ' (Lau, 1997) offers a wider range of potential benefits to financial institutions (Howcroft \& Durkin, 2000; KPMG, 1998; Mols, 1998) due to more accessible and user friendly use of the technology, as the Internet does not restrict banks to physical locations or historical geographical areas. Also The Internet has opened a window of opportunity to almost anyone because of its ability to make viable the conduct of business in virtual space, or by connecting people worldwide 
without geographical limitations. Consumers can order goods and services virtually anywhere, 24 hours a day, 7 days a week without worrying about store hours, time zones, or traffic jams (Gilani Nia et al., 2011). The technology therefore allows banks to think and operate in new geographical zones with new markets, market spaces and product scopes. New fee-based income generated from improved or new services such as advertising, bill presentment, alerts, and notifications and customised information is attractive to modern banks. Such activities provide added value for the customer and opportunities for banks to bolster income streams and secure longer term customer loyalty, through relationship management. Components for electronic banking services that are bank clients include:

A) The types of cards:

1. Cards with magnetic strips

2. Cards with electronic chips

3. Cards with Processor chip

B) Acceleration Network

The online network is a national, and performs services related to e-cards. Domestic debt Cards for settlement provides among banks.

c) Settlement system of foreign exchange inter-bank

The system works by using the SWIFT on line between central branches of commercial banks.The central bank is responsible for role of settlement.

D) Switching network actions micro-banking and among banking

E) Central network SWIFT

\section{Research Hypotheses}

1- There is significant relationship between attitude behavior and behavioral tendency in acceptance of electronic banking.

2- There is significant relationship between subjective norm and behavioral tendency in acceptance electronic banking.

3- There is significant relationship between perceived behavioral control and behavioral tendency in acceptance electronic banking.

4- There is significant relationship between elements of the planned behavior theory in acceptance electronic banking.

\section{Research Methodology}

In terms of methodology and implementation of research is descriptive - analytical and causal analysis and in terms of type monitoring and degree of control is the field research. Questionnaire of research is validated because validate or validity of it has confirmed by supervisors and consultants of faculty. In practice to calculate the reliability coefficient of questionnaire, the first prototype of 20 questionnaires a pre-test. Then, using data obtained was calculated Cronbach's alpha coefficient. Questionnaire to measure the reliability of each variable using Cronbach's alpha coefficient was greater than $70 \%$ shows that questionnaire is reliability. In this study, the research hypotheses were tested using the Pearson correlation coefficient.in this study community is all users of Internet banking services and credit card bank in Saderat bank of Iran (Rasht).Sampling in the study is non- possible availability. The number of samples is 384 .

$\mathrm{n}=\frac{a_{\frac{\alpha}{2}}^{2} p Q}{\mathrm{~d}^{2}}=\frac{1.96^{2} 0.2 \mathrm{E}}{0.0 \varepsilon^{2}} \cong 384$

\section{Data Analysis}

The respondents were $74 / 2 \%$ male and $25 / 8$ percent female.

4 / 9 percent of respondents have a Diploma, 19/8\% Associate Degree, 61/7 bachelor's degree, 9/1 percent have Master of degrees and higher.

45/1 percent of respondents under 30 years,34/9 percent between 30 to 40,8 / 12 percent 40 to 50,7/3 \% more than 50 years old.

$<$ Table 1 about here>

1- After analysis first hypothesis by using regression such was inferred that there is a significant relationship between attitude behavior of Saderat Bank customers and Behavioral tendency in the use of electronic banking. So relation intensity is 29.2 percent . Other words 8.5 percent change in consumer behavioral tendency to be explained by the attitude behavior. Means that behavioral tendency increase with increased Attitude behavior into customer behavior. And 
since Sig $(2-$ (tailed) $=0 / 000<0.05$ is, then test statistics is in critical area. And therefore we can say that Ho hypothesis is rejected and $\mathrm{H} 1$ is accepted.

2- In analysis second hypothesis by using regression such was inferred that there is a significant relationship between subjective norm of Saderat Bank customers and behavioral tendency in the use of electronic banking. So relation intensity is 75 percent . Other words 56.3 percent change in consumer behavioral tendency to be explained by the Subjective norm. Means that behavioral tendency increase with increased Subjective norm into customer behavior. And since Sig $(2-$ (tailed) $=0 / 000<0.05$ is, then test statistics is in critical area. And therefore we can say that Ho hypothesis is rejected and $\mathrm{H} 1$ is accepted.

3- After analysis third hypothesis by using regression such was inferred that there is a significant relationship between perceived behavioral control of Saderat Bank customers and Behavioral tendency in the use of electronic banking. So relation intensity is 79.7 percent .Other words 63.5 percent change in consumer behavioral tendency to be explained by the perceived behavioral control. Means that Behavioral tendency increase with increased perceived behavioral control into customer behavior. And since Sig ( 2 - (tailed) $=0 / 000<0.05$ is, then test Statistics is in critical area. And therefore we can say that Ho hypothesis is rejected and $\mathrm{H} 1$ is accepted.

4- In the fourth hypothesis, the results of the Pearson correlation test strongly relation is 83.3 percent between elements of planned behavior and behavioral tendency to accept e-banking. . and since sig ( 2 - (tailed) $=0 / 000<0.05$ is, then test statistics is in critical area. and therefore we can say that ho hypothesis is rejected and h1 is accepted. such was inferred that there is a significant relationship between elements of planned behavior and behavioral tendency in the use of electronic banking. according to the beta coefficient, in terms of relation intensity, perceived behavioral control is in the first rank, and norms of behavior and mental attitudes are the second and third in the rankings.

\section{Conclusions and Suggestions}

The use of electronic cards and payment methods via Internet Banking and Also provides people daily commodity through e-commerce can be an effective step in the livelihood of the people and governments. Also the authorities should be effective with a closer look consideration of the benefits of this emerging industry in the country with the implementation of appropriate policies in this culture .Today's customer-oriented is considered Policies in the comprehensive field of administration, business and industry required, that banks offering a variety of credit cards and payment systems and mobile Internet, provide e-business development and growth. In this connection if it should be carefully that the nature of e-business operations, is similar to international business operations in terms of telecommunications and indirect ,Then it would be conceivable that a wide range of financial services and credit Also issuance of the warranty, insurance and other types of financial intermediation by banks and credit institutions Not only for international transactions but also it is in domestic contracts for the supply of a country and if they offer this service market in which business is placed on the Electronic will be go forward to safe. In fact Customer Orientation in the digital Banking is an example of e-democracy approach. Thus the creation of electronic equipment and facilities necessary and the use of electronic funds transfer system causes that improve Relations between enterprises and banks with their customers because increased speed of operation and reduced errors and lower costs makes That customers are encouraged to communicate with organizations and institutions because they use of electronic funds transfer systems.

The use of electronic bank cards and methods of payment via the internet and also provides daily commodity of people through e-commerce can be an effective step in the livelihood of the people and governments. The government should look more carefully and considering the advantages of this new industry in the country with appropriate implementing policies in this culture is role modeling. According to the results suggest that:

- Due to the positive relationship between two variables attitude behavior and behavioral tendency in acceptance of electronic banking suggest that production of promotional teaser and use of reference groups in creating a positive attitude in the tendency to use e-banking. Using electronic banking should be institutionalized as a wise idea in mind and can make good and positive feel in person.

- Due to the positive relationship between two variables subjective norm and behavioral tendency in acceptance of electronic banking can be effective strategies employing family members, close friends and important people in make tendency to use of electronic banking. Therefore, studies have been proposed with interpersonal influence strategies.

- Due to the positive relationship between two variables perceived behavioral control and behavioral tendency in acceptance of electronic banking suggest that banks try to increase their knowledge and skills customers in the use of e-banking. To building educational and notification teaser, creating a customer club and provide mechanisms in the branches can be very effective in order train to customers for potential synergy. 


\section{References}

Ajzen, I. (1991). The theory of planned behavior. Organ Behav Hum Dec Proc. 50(2):121-79. http://dx.doi.org/10.1016/0749-5978(91)90020-T

Ajzen, I. (2002). Perceived Behavioral Control, Self-efficacy, Locus of Control, and the Theory of Planned Behavior1. p. 665-83.

Ajzen. (2002). Behavioral interventions based on the theory of planned behavior. Journal of the Association for Information Systems.

Akinci, S., Aksoy, S., \& Atilgan, E. (2004). Adoption of Internet banking among sophisticated consumer segments in an advanced developing country. International Journal of Bank Marketing, 22(3), $212-232$. http://dx.doi.org/10.1108/02652320410530322

Aladwani, A. M. (2001). Online banking: A field study of drivers, development challenges, and expectations. International Journal of Information Management, 21, 213-225. http://dx.doi.org/10.1016/S0268-4012(01)00011-1

Amirkhani et al. (2011). The TAM models application in technology transition. Interdisciplinary Journal of Contemporary Research in Business,vol 3,no 3.

Bauer, K., \& Hein, S. E. (2006). The effect of heterogeneous risk on the early adoption of Internet banking technologies. Journal of Banking and Finance, 30, 1713-1725. http://dx.doi.org/10.1016/j.jbankfin.2005.09.004

Boniadi.(2007). The importance of effective communication with customers in e-banking. Conference on Electronic Banking.

Booz, Allen, \& Hamilton (1997). Internet Banking: A global study of potential. New York, NY: Booz, Allen \& Hamilton Inc.

Chan, S.C., \& Lu. M.T. (2004).Understanding internet banking adoption and use behavior: a Hong Kong perspective, Journal of Global Information Management 12 21-43. http://dx.doi.org/10.4018/jgim.2004070102

Cheng, T. C. E., Lam, D. Y. C., \& Yeung, A. C. L. (2006). Adoption of Internet banking: An empirical study in Hong Kong. Decision Support Systems, 42(3), 1558-1572. http://dx.doi.org/10.1016/j.dss.2006.01.002

Claessens, J., Dem, V., De Cock, D., Preneel, B., \& Vandewalle, J. (2002). On the security of today’s online electronic banking systems. Computers and Security, 21(3), 257-269. http://dx.doi.org/10.1016/S0167-4048(02)00312-7

Dannenberg, M., \& Kellner, D. (1998). The bank of tomorrow with today’s technology. International Journal of Bank Marketing, 16(2),90-97. http://dx.doi.org/10.1108/02652329810206743

Davis, F. , Bagozzi , R., Warshaw, P. ( 1989). User acceptance of computer technoloy: a comparison of two theoretical models.

Deloitte Consulting (1998). Competing for your customers: The future of retail financial services. Deloitte Consulting.

Fethi, C., Cigdem, A. G. (2008). Internet banking versus other banking channels: Young consumers’ view. International Journal of Information Management, p215-221

Giannakoudi, S. (1999). Internet banking: The digital voyage of banking and money in cyberspace. Information \& Communications Technology Law, 8(3), 205-243. http://dx.doi.org/10.1080/13600834.1999.9965811

Gilani, N., Shahram, G., Majid, M., \& Seyed, J. (2011). Comparison of adaptive internet and traditional marketing mix the willingness to buy cultural products. Interdisciplinary Journal of Contemporary Research in Business,vol 3,no 3.

Harrison, D.A., Mykytyn, P.P., \& Riemenschneider, C.K. (1997). Executive decisions about adoption of information technology in small businesses: Theory and empirical test. Information Systems Research, 8(2), 171-195. http://dx.doi.org/10.1287/isre.8.2.171

Howcroft, B., \& Durkin, M. (2000). Reflections on bank-customer interactions in the new millennium. Journal of Financial Services Marketing, 5(1), 9-20. http://dx.doi.org/10.1057/palgrave.fsm.4770002

Hu, P.J., Chau, Y.K., Sheng, L.R.,\& Tam, K.Y. (1999). Examining the technology acceptance model using physician acceptance of telemedicine technology. Journal of Management Information Systems, 16( 2), 91-112.

Kalakota, R., \& Whinston, A. (1997). Electronic commerce: A manager’s guide. Reading, Mass: Addison Wesley.

Lai, V. S., \& Li, H. (2004). Technology acceptance model for Internet banking: An invariance analysis. Information and Management, 42, 373-386. http://dx.doi.org/10.1016/j.im.2004.01.007 
Lau, E. [Speech on 30 September 1997]. Government policy on smart card applications and Internet Banking. Hong Kong Monetary Authority

Lee, M. (2009). Factors influencing the adoption of internet banking :an integration of TAM and TPB with perceived risk and perceived benefit. Journal of Electronic Commerce Research and Applications,8,p 130-141

Lu, .J., Liu, C., \&Yao, J. (2003). Technology Acceptance Model for wireless internet. Electronic Networking Applications and Policy, vol 13, No3.

Luarn, P., \& Lin, H. (2005). Toward an understanding of the behavioral intention to use mobile banking. Computers in Human Behavior, 21(6), 73-91. http://dx.doi.org/10.1016/j.chb.2004.03.003

Mathieson, K. (1991). Predicting user intentions: Comparing the technology acceptance model with the theory of planne behavior. Information Systems Research, 2(3), 173-191. http://dx.doi.org/10.1287/isre.2.3.173

Mols, N. P. (1998). The behavioral consequences of PC banking. International Journal of Bank Marketing, 16(5), 195-201. http://dx.doi.org/10.1108/02652329810228190

Mols, N. P. (1998). The Internet and the banks' strategic distribution channel decisions. International Journal of Bank Marketing, 17(6),295-300. http://dx.doi.org/10.1108/02652329910300341

Onguasuwan, M.(2000). A comparative study of internet Banking in Thailand. Asian university of science and thechnology , Faculy of Business, Mis Department, Thailand.

Taylor, S.,\& Todd, P. (1995). Understanding information technology usage: A test of competing models. Information systems research, 6176-144-(2).

Wisner, J. D., \& Corney, W. J. (2001). Comparing practices for capturing bank customer feedback: Internet versus traditional banking. Benchmarking: An International Journal, 8(3), 240-250.

Yakhlef, A. (2001). Does the Internet compete with or complement bricks and mortar bank branches? International Journal of Retail and Distribution Management, 29(6), 272-281. http://dx.doi.org/10.1108/09590550110393965

Table 1. Results of Pearson correlation coefficient testing

\begin{tabular}{|c|c|c|c|c|c|}
\hline \multicolumn{2}{|c|}{ Research hypotheses } & $\mathrm{R}$ & $\mathrm{B}$ & SIG & Hypotheses status \\
\hline \multicolumn{2}{|c|}{ The first hypothesis } & .29 & .44 & .000 & confirmed \\
\hline \multicolumn{2}{|c|}{ The second hypothesis } & .75 & .43 & .002 & confirmed \\
\hline \multicolumn{2}{|c|}{ The third hypothesis } & .79 & .57 & .000 & confirmed \\
\hline \multirow{3}{*}{ The fourth hypothesis } & Attitude behavior & \multirow{3}{*}{.833} & .166 & .001 & \multirow{3}{*}{ confirmed } \\
\hline & Subjective norm & & .213 & .000 & \\
\hline & Perceived behavioral control & & .406 & .000 & \\
\hline
\end{tabular}

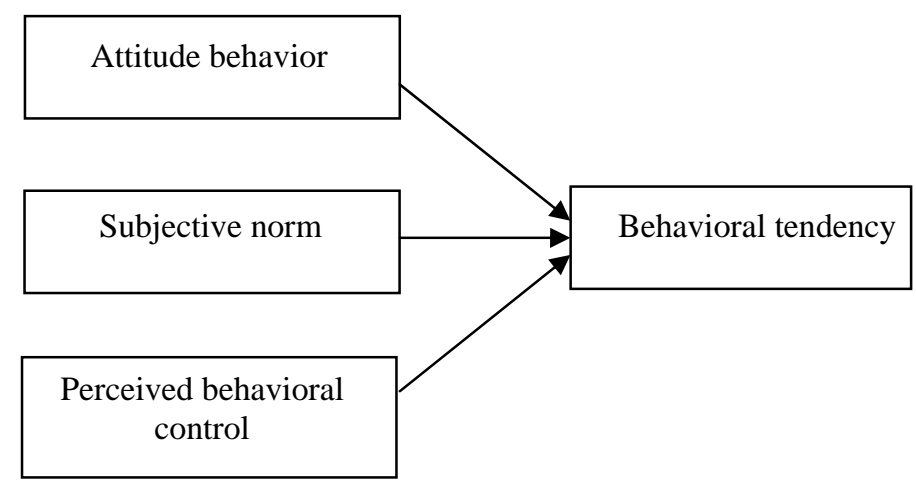

Figure 1. Theory of planned behavior model 